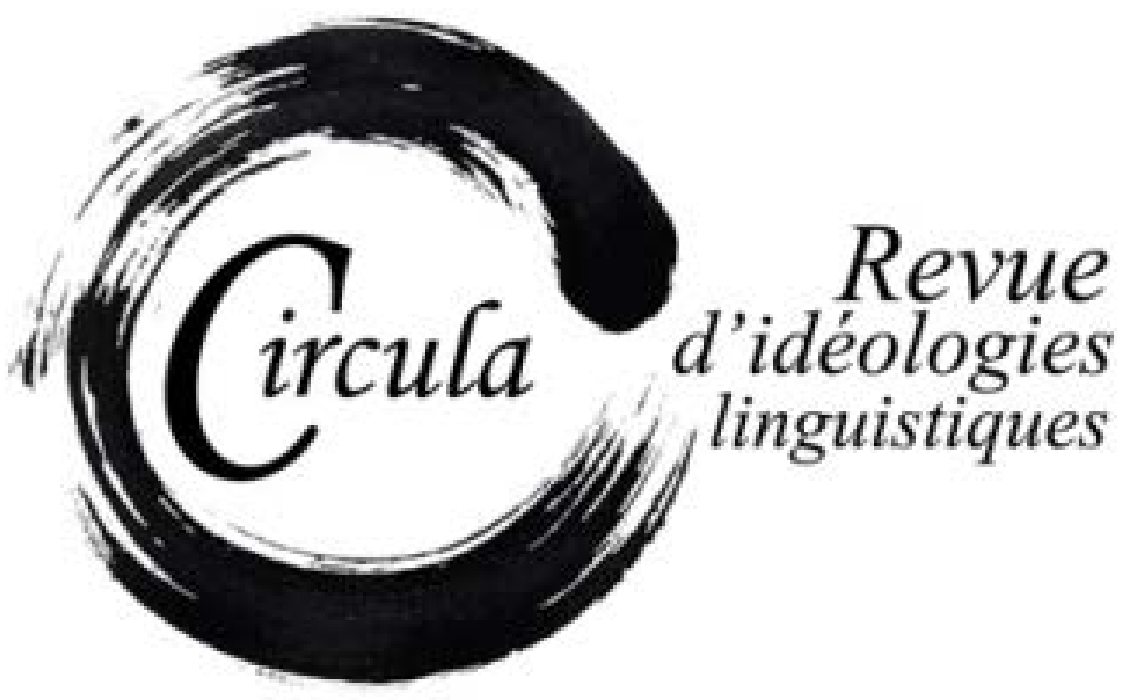

TITRE: LA IMPERIAL EÑE: PURISMO E IDEOLOGía EN LOS ARTíCulOS DE OPINIÓN del Último CAMILO JosÉ CELA

Auteur(s): Carlos Frühbeck Moreno, Universitá degli Studi di EnNA "Kore"

Revue: Circula, numÉRO 2, PAGES 31-54

ISSN: 2369-6761

DiRecteurs: Wim REMYSEn et SABINE SCHWARZE

URI: HTTP://HDL.HANDLE.NET/11143/7983

DOI: $10.17118 / 11143 / 7983$ 


\section{La imperial eñe: purismo e ideología en los artículos de opinión del último Camilo José Cela}

Carlos Frühbeck Moreno, Universitá degli Studi di Enna "Kore"

moreno.fruhbeck@unikore.it

Resumen: En este trabajo nos ocuparemos de los artículos de opinión publicados en el periódico español ABC por Camilo José Cela con el título de "El color de la mañana”. Asimismo, apoyaremos nuestro estudio con referencias a otras obras, como Los sueños vanos, los ángeles curiosos (1979) o Viaje al Pirineo de Lérida (1965). Buscaremos demostrar que el premio Nobel de Literatura plantea una ideología lingüística cercana a la del nacionalismo clásico: la lengua española posee una forma interior que se capta intuitivamente, y una serie de virtudes intrínsecas que la hacen mejor que las demás. Y, por añadidura, al pueblo con el que se identifica con respecto a los otros. Por tanto, va protegida tanto de la contaminación externa que acecha la identidad de sus hablantes como de la amenaza interna que amenaza el mutuo entendimiento. Y los encargados de su protección y planificación deben ser los escritores y no los lingüistas, visto que los primeros son los únicos que disponen de la intuición necesaria para comprenderla.

Palabras clave: Camilo José Cela; ideologías lingüísticas; nacionalismo; artículo de opinión

Abstract: In this paper we deal with the opinion articles published in the Spanish newspaper $A B C$ by Camilo José Cela under the title of "El color de la mañana”. We will also support our study with references to other works such as Los sueños vanos, los ángeles curiosos (1979) or Viaje al Pirineo de Lérida (1965). We shall demonstrate that Cela deploys a kind of language ideology very close to classical nationalism: the Spanish language possesses an inner form which ought to be captured intuitively, and a series of intrinsic virtues that make it better than others. Moreover, the people speaking this language become therefore better than others. Therefore, it is protected both from external contamination lurking their speaker's identity and the internal factors that put mutual understanding in jeopardy. And those charged with their protection and planning should be the writers and not the linguists, given that only the former are those with the necessary intuition to understand it.

Keywords: Camilo José Cela; language ideologies; nationalism; opinion article 


\section{Introducción}

Camilo José Cela fue un agente de política lingüística de primer orden en la España democrática, a pesar de su pasado de colaborador con el régimen franquista, entre otros aspectos, como censor entre 1943 y 1944 (Sinova, 2006: 150), y como representante cultural en América Latina a través del encargo y redacción de La Catira (v. Guerrero, 2008). Todo ello en el contexto de una evolución ideológica algo ambigua hacia un "conservadurismo liberal y algo misoneísta" a partir de los años 50 (Alvar, Mainer y Navarro, 1997: 641-642). Entre otros factores, la concesión del Premio Nobel de Literatura en 1989 y la creación de un personaje que combinaba al Académico con el escritor "rebelde" y amante del casticismo, le dieron una importancia tal que acabó por convertirse en todo un símbolo de la cultura española (v. Gibson, 2004). Es por eso que fue elegido para inaugurar los Congresos de la Lengua Española de Zacatecas en 1997 y de Valladolid en 2001, algo que realizó con un único autoplagio de un texto de 1992 (Rojo y Mora, 2001).

El escritor distó mucho de adaptarse a concepciones de la lengua que superaran el nacionalismo. En concreto, los contenidos de este discurso (Cela, 2001) ya nos mostraban una ideología lingüística ${ }^{1}$ muy diferente de la que promovía una España en pleno proceso de modernización y que entendía la lengua como instrumento de entendimiento y concordia (Del Valle, 2007a: 37-41). Más bien Cela habla de un español que se "enseña" a los otros pueblos y denuncia la perenne amenaza bajo la que se encuentra sobre todo por parte de sus propios hablantes, que parecen avergonzarse de hablarlo y que, por ello, renuncian a su identidad. Es decir, nos encontramos con un ejemplo de pervivencia de discursos puristas precisamente en el momento en que se constituía una comunidad discursiva que promovía ideas muy diferentes (Del Valle, 2007b: 89-93). Una voz arcaica en la esfera pública en la que se debatía la naturaleza del español.

En las colaboraciones que el escritor publicó de forma más o menos esporádica en $A B C$ bajo el título de "El color de la mañana" entre el 21 de noviembre de 1993 y el 13 de enero de 2002, pocos días antes de su muerte, nos encontraremos con una voz que combina esta ideología lingüística nacionalista con una ideología conservadora y, quizá, antimoderna, refractaria al proceso de modernización que se estaba viviendo en España durante aquellos años. El corpus consultado en la Hemeroteca de $A B C$ está formado por 412 textos de muy desigual extensión publicados con una periodicidad irregular que se va espaciando a lo largo de los años. De hecho, 360, es decir, el 87\% del corpus consultado, se publicaron entre el 21 de noviembre de 1993 y el 31 de diciembre de 1996.

La elección de un corpus de artículos de opinión más o menos heterogéneos para el estudio de las ideas de Cela sobre la lengua y su uso responde a motivos muy concretos: en primer lugar, las características del género elegido, que se presenta como el medio idóneo para que un escritor convertido

1. A pesar de lo complejo de su definición, en este trabajo entenderemos por ideología lingüística un conjunto más o menos ordenado de juicios o imágenes del idioma que en muchas ocasiones responde más a un orden externo que a cuestiones intrínsecamente lingüísticas. Toda ideología opera desde el interior del mundo social pero se muestra como descripción el mismo (v. Woolard, 2001, 2007). 
en símbolo pueda transmitir sus ideas a un público amplio. Tal y como señala Manuel Hidalgo, este tipo de género se sustancia en:

La expresión de una voz y una mirada personales que se manifiesta con sesgo literario rubricado con firma, sobre alguna parcela de la realidad con relativa brevedad, con asiduidad, en espacio propio, diferenciado y fijo y con libertad de criterio, estilo y forma (citado en Seoane, 2008: 23-24).

Es decir, gran parte de la eficacia persuasiva de un artículo literario pasaría por la capacidad del autor para presentarse como alguien digno de crédito a través de la articulación de una voz diferente en la propia escritura, de la creación de un ethos que es capaz de proyectar eficazmente una concepción del mundo y una ideología sobre un público muy definido (v. López Pan, 1996: 59 y ss), en este caso los lectores conservadores de ABC. Por su parte, León Gross (1996: 179) afirma que el artículo de opinión consiste en oponer la propia singularidad a las tesis comúnmente aceptadas. Camilo José Cela plantea una poética similar a todo lo dicho en su primera colaboración:

[E]l mundo está en guerra, esa cotidiana vulgaridad sin sentido común, pero, al margen de los estruendos y las infamias, también brilla una leve oleada de paz pintada con ese color que cada día veo y me reconforta; en él quisiera mojar mi alma y encontrar la palabra con la que, bien adiestrado en el oficio, asomarme casi diario a estas páginas con el pensamiento puesto en la buena intención, ese premio que los dioses sólo regalan a quienes distinguen (Cela, ABC, 21 de noviembre de 1993).

El autor se presenta desde el primer momento como alguien que debe ser escuchado por estar dotado del sentido común necesario para oponerse a las inercias de la realidad. Por tanto, las características del género y la consolidación del personaje público de Cela², con su escritura tan fácilmente reconocible, otorgaban una amplia libertad para la expresión de sus ideas. En nuestro trabajo nos centraremos sobre todo en aquellas que hacen referencia al lenguaje y a su uso.

\section{El juego de las renuncias y las abdicaciones}

Quizá sea posible definir el nacionalismo si tomamos como punto de partida la idea de un mundo dividido naturalmente en naciones entendidas como comunidades unitarias y autónomas que poseen una identidad diferenciada y estable. Se trataría de las comunidades imaginadas que postula Benedict Anderson (1993: 17-25), y cuyo desarrollo a lo largo del tiempo relaciona con la diversidad lingüística, el afianzamiento del capitalismo y la invención de la imprenta, con la correspondiente creación y fijación de una lengua impresa. De hecho, uno de los factores fundamentales en el nacimiento y triunfo del nacionalismo es la existencia de una lengua vernácula que se usa

2. Tampoco podemos olvidar la amplia y polémica experiencia de Camilo José Cela como colaborador en prensa, algo que para el escritor supuso una manera de mantenerse continuamente en contacto con sus lectores, y también una tensión entre la voluntad artística de escribir un texto perdurable y el carácter efímero del género (Valls, 2002). 
como elemento centralizador de la administración (v. Burke, 2006: 88-110). La naturaleza de esta comunidad se concreta en los límites de un territorio, en la soberanía compartida de sus miembros y en un sentimiento de hermandad entre seres que nunca llegarán a conocerse.

La lengua sería uno de los elementos que más ayudarían a crear este sentimiento imaginario de unión. De hecho, Peter Burke ya señala en su análisis sobre la relación entre lengua y comunidad durante la Edad Moderna la asociación entre características lingüísticas y carácter de las naciones (2006: 34-36) dentro de un contexto de competición por la supremacía (2006: 82-84). La identificación entre comunidad, nación y lengua adquirirá una importancia mayor todavía a partir de 1880, cuando el aumento de los desplazamientos de población y la democratización de la política, con la necesidad de crear mecanismos que facilitaran la intervención del pueblo en los asuntos del Estado, hicieron que el nuevo nacionalismo centrase su discurso en los criterios lingüístico y étnico ante la necesidad de dar una mayor homogeneidad cultural a la sociedad (Del Valle y Gabriel-Stheeman, 2004c: 8). De esta forma, la lengua estándar se convirtió a la vez en garantía de cohesión interna y de diferencia con respecto al exterior. Es decir, se promovió una cultura monoglósica (v. Del Valle, 2000).

Si partimos de la premisa romántica de que estas comunidades encuentran su realización en la expresión de su autenticidad (Smith, 2010: cap. 2) en la historia, el vínculo entre lenguaje y nación se sustanciaría en el Romanticismo en la condición herderiana del primero como "herencia colectiva", como elemento aglutinador y preservador de la diferencia del pueblo que lo utiliza con respecto a las demás (Edwards, 2009: 208-210). A pesar de que a lo largo de la historia la elección de la variedad lingüística que es vehículo de expresión nacional haya sido determinada por factores que poco tienen que ver con sus características (v. Anderson, 1993: 68-72), su consideración como elemento unificador de la comunidad nacional hará que se la sitúe en una posición de superioridad por razones "intrínsecas" tanto con respecto a las otras variedades presentes en el territorio nacional como con respecto a otras lenguas. En palabras de Moreno Cabrera,

el nacionalismo lingüístico se caracteriza por asignar una justificación natural e inevitable a los procesos históricos que dieron lugar al predominio de una determinada variedad dialectal, dialecto, koiné o lengua, o como se la quiera llamar, dado que este predominio se ve como el resultado de una superioridad lingüística por las características gramaticales de la lengua en cuestión y de una superioridad de la actuación lingüística de los hablantes de esa lengua, dadas sus intenciones más certeras; lo cual además está asociado a la superioridad de la nación en otros terrenos más importantes. (Moreno Cabrera, 2008: 83)

Creemos que estas serían las coordenadas más adecuadas para situar una primera lectura que Camilo José Cela realiza de nuestra lengua: se trata del principal elemento diferenciador que poseemos con respecto a otras naciones y, sobre todo, define de tal forma nuestra pertenencia a una comunidad que, sin ella, nos vemos incapaces de expresarnos, de emocionarnos: 
Yo siempre admiré mucho a los daneses, personas que conseguían entenderse y vivir en danés, idioma que más que una lengua parece una enfermedad de la garganta, pero ahora amplío tanto mi admiración como mi respeto a los checos, seres que son capaces de silabar palabras sin vocales. Quienes hablamos lenguas fáciles, sonoras y naturales, las latinas, por ejemplo [...] no solemos emocionarnos lo suficiente ante los parlamentos de los hablantes [...] en otras lenguas para nosotros herméticas, aún casi rituales y mucho menos que crípticas. [...] Me reconforta pensar que en español tenemos, al menos, una palabra murciélago, contenedora de todas las vocales. (Cela, ABC, 26 de junio de 1994; las cursivas son nuestras)

Salta a la vista que es como mínimo arriesgado afirmar que las cinco vocales del español son todas las vocales posibles, como si ese fuera el único límite de todos los sistemas fonológicos. El juicio sobre la supuesta dificultad de un idioma es siempre discutible e inevitablemente depende del punto de vista (v. Moreno Cabrera, 2000: 115-136). Más bien lo que nos interesa es que el sistema vocálico se utiliza para justificar la superioridad del español sobre otros idiomas. Por otra parte, los demás criterios para establecer la diferencia entre lenguas son también, como mínimo, muy subjetivos.

Sin embargo, las afirmaciones de Camilo José Cela tienen unos precedentes bien definidos en la tradición filológica española. En particular, nos referimos a la lectura ideológica que realizó Menéndez Pidal del castellano como lenguaje moderno al plantearlo, con el arma del análisis científico, a la vez como símbolo de un pasado glorioso - la lengua que solo podía pertenecer a un reino enérgico e innovador como el castellano - y como instrumento armónico capaz de proyectar a sus hablantes a un futuro de progreso (v. Del Valle, 2004), que ya se leía en la Edad Media en una evolución "privilegiada" con respecto al resto de los dialectos hablados en la península. Así, entre otros muchos ejemplos, en su artículo "Carácter originario de Castilla" el filólogo gallego afirma que:

En suma, la Castilla primitiva en su lenguaje, lo mismo que en la política y la guerra, lo mismo que en el derecho, se adelantaba a cumplir una evolución que estaba destinada a triunfar. Iba guiada por un fino sentido selectivo que atinaba pronto con aquellas formas que más tarde prosperarían también espontáneamente en los dialectos circunvecinos, o con aquellas más peculiares que mejor podrían ser aceptadas por los demás. (Menéndez Pidal, 1944: 398)

Tal y como señala Moreno Cabrera (2008: 78-80), para Menéndez Pidal, esta naturaleza del idioma, su capacidad de dominio sobre otros se hace visible en su sistema fonológico, que lo haría más estable que el resto de las lenguas. Idea esta que, a pesar de su impresionismo, ha tenido un profundo calado en la tradición científica española. Así, en palabras de Gregorio Salvador, "buena parte del éxito del castellano hay que atribuírselo a sus cinco vocales netamente diferenciadas, el sistema vocálico más perfecto de los posibles, sin vocales mixtas ni intermedias, sin sensibles diferencias de intensidad" (citado en Moreno Cabrera, 2008: 79). 
En resumidas cuentas, nuestro idioma no solo será superior a los demás sino que será el único medio posible que tendremos a nuestra disposición para poder ser nosotros mismos. Esto llevará a Camilo José Cela a tomar una postura un tanto paradójica para un bilingüe como él al reflexionar sobre la importancia del aprendizaje de idiomas extranjeros durante la crónica de un viaje a Tokio: "Esto de no saber lenguas tiene sus incomodidades, es cierto, sobre todo a la hora de pedir el desayuno en los hoteles, pero evita el que tengamos que pasarnos la vida fingiendo y sonriendo" (Cela, ABC, 5 de Abril de 1998).

Por todo esto, nuestra primera aproximación al concepto de lengua de Camilo José Cela nos sitúa en el ámbito de la ideología lingüística de la autenticidad en la que el habla es percibida como "una proyección de la persona misma” (Woolard, 2007: 132) y como una expresión del espíritu de su comunidad. No es por eso sorprendente que aprender otros idiomas pueda ser un riesgo para la propia naturaleza (Woolard, 2007: 132) y que, como veremos a continuación, se pueda establecer una correspondencia biunívoca entre usos lingüísticos y valores morales. De esta forma, el uso lingüístico será un elemento suficiente para indexar un grupo social (Irvine y Gal, 2000: 37) y el juicio sobre los primeros versará sobre aspectos tan ajenos al idioma como emociones, costumbres e identidades (v. Gal, 1998: 324ss).

Junto con esta fuerte identificación entre lengua e identidad en nuestro corpus hemos detectado una fuerte tendencia purista. No en vano, al analizar el purismo lingüístico, George Thomas considera el nacionalismo como el principal factor extralingüístico que lo determina, al partir de una concepción inmovilista de la identidad y de la cultura (Thomas, 1991: 135-136). Con estas premisas, ya es posible preguntarnos quiénes son los enemigos contra los que combate Camilo José Cela y cuál es su naturaleza. Nuestra primera respuesta es que el purismo de Camilo José Cela está orientado hacia el nivel léxico-semántico y es de corte xenofóbico (v. Thomas, 1991: 80-81) y que, de forma coherente con todo nuestro razonamiento, un primer objetivo son los préstamos de lenguas extranjeras, en particular del inglés (v. Thomas, 1991: 68-69).

Cela establece continuamente una identificación entre usos lingüísticos y características morales de los sujetos a través de la estrategia de la iconización (Irvine y Gal, 2000: 37). Un buen ejemplo de esto son los artículos, "Matías y Eulogio, o sea Fred y Ted" (Cela, ABC, 16 de diciembre de 1994) e "Insistiending" (Cela, ABC, 3 de enero de 1995) en los que se narra la vida de una pareja de homosexuales con una prosa en la que el anglicismo se usa de forma masiva:

Fred y Ted hablan cada día mejor el inglés, es un decir; en las sleeping citys de las afueras se puede practicar con mucho aprovechamiento la lengua de Carter, de Reagan y de Clinton, también de Fred Astaire, de John Wayne y de Frank Sinatra, y así el que no prospera es porque no quiere, yo cumplo insistiending en el prudente consejo. A Fred y a Ted, después de iniciarse en los arcanos del marketing, del consulting y del advertising, ya es sabido que en los pubs, en los burger y en los snacks, se nutre el mailing y se aprende mucho, están ahora estudiando, digamos, factoring, confirming y forfaiting y, si las cosas les siguen yendo bien 
piensan enfrentarse a las complejas y soterradas raíces del leasing y el franchising, sin despreciar, claro es, el hedging y el trading, que tampoco están mal. (Cela, ABC, 3 de enero de 1995)

Son conocidas las opiniones despreciativas de Camilo José Cela en lo que se refiere a los homosexuales, tanto a través de la declaración pública, como lo fue la crítica de su presencia en los homenajes a Federico García Lorca con motivo de su centenario (Hermida, 1998), como en su caracterización como personajes literarios a través de, por ejemplo, la creación de antropónimos (Lopatina, 2011: 280). De la lectura del artículo se deduce que todas las profesiones que se denominan con un anglicismo son propias de homosexuales, algo que nos informa de forma bastante precisa sobre la sociedad ideal del autor. Asimismo, es también relevante el hecho de que los dos protagonistas hayan cambiado sus nombres "carpetovetónicos" - Matías y Eulogio - por dos nombres ingleses y que, ambos, a pesar de su vocación, al final tengan unos conocimientos de inglés bastante rudimentarios: "iEres un sol, Ted! Llamarte darling es poco! ¿Tú crees que amor mío se dirá amorming en la lengua de los Beatles?" (Cela, ABC, 16 de diciembre de 1994). Así nos encontramos con esta idea de que la pérdida de nuestro idioma es una condena al silencio - nunca podremos tener una identidad alternativa a la que nos ofrece - y que solo renuncian al mismo los grupos no deseados de la sociedad.

Quizás el punto de intersección entre grupo social y uso lingüístico más llamativo para Cela sea el nombre propio. Efectivamente, tal y como señala Edwards (2009: 34-36), a pesar de la arbitrariedad inherente a la asignación de un nombre, resulta complicado no ver en el mismo una motivación. Así, en "Recuerdo de tres amigas", el escritor presenta con ironía a tres flamencas llamadas Samantha, Vanessa y Gwendolyn, señalando que "a consecuencia de la democracia, tienen derecho al voto y hasta pueden ser elegidas, concejalas, diputadas, senatrices, como si fueran suecas o inglesas" (Cela, ABC, 9 de septiembre de 1994; las cursivas son nuestras). En el artículo se nos presentan tres mujeres con el pelo teñido "color espagueti", que hablan "medio en español, medio en lo que [sea]". Además, para el autor, estas mujeres necesitan "un hombre que las ate en corto para que no se desmanden". Lo que contrasta irónicamente con su derecho al voto. Durante una cena, la esposa de Cela les ofrece trabajo como limpiadoras. Obviamente, al final ellas lo rechazan para dedicarse a la política. Y su naturaleza queda definida en el neologismo que hemos subrayado.

Este rechazo a las lenguas extranjeras y a la adopción de préstamos enlaza con un antieuropeísmo que el autor relaciona con una oposición al estado de bienestar y a los cambios que trae la modernidad. Todo ello se combina con una nostalgia por una sociedad cuyo fundamento reposaba en la tradición. Los ejemplos son muy numerosos. Elegimos uno de los más explícitos. Hablan los estados del Norte de Europa sobre el destino de España:

- ¿Y qué haremos con los españoles?

- Pues, nada, lo previsto, enseñarles inglés y alemán a nuestros hijos, jamás latín, claro, porque podría inducirles al discernimiento y a sus secuelas la desobediencia y la subversión, 
y adiestrarlos en el uso de las computadoras: un buen camarero debe saber quién quiere pepsicola o jugo de tomate, algunos piden whisky on the rocks, y también debe aprender en abyecta sumisión la lengua que se le ordene. (Cela, ABC, 22 de octubre de 1995)

Con estas premisas, Cela participa de la llamada complaint tradition, la tradición alarmista que ve siempre la lengua amenazada, en peligro de muerte (Milroy y Milroy, 1999: 39-46). El idioma español se encuentra en una situación de emergencia de tal gravedad que sería una grandísima imprudencia dejar su evolución en manos de sus hablantes, que acabarían siendo responsables de su contaminación y de su pérdida. La entrada de extranjerismos es sinónimo de vergüenza por la propia identidad:

Es lástima que acontezca, y también lo es decirlo, pero es verdad: los deportistas españoles - y en general los españoles aún no deportistas - desprecian nuestra eficaz y gloriosa lengua, parece como si les diera vergüenza usarla y pregonarla, y tienden a hablar en inglés [...] acomodando a veces las palabras a nuestra ortografía o incluso importándolas tal cual. (Cela, $A B C, 9$ de julio de 1995)

Este pequeño sermón no tiene más objetivo que sugerir que en un manual de pesca sería aconsejable que el black bass sea denominado "perca americana". Como es previsible, su denuncia se extenderá a los medios de comunicación de masas, en los que los periodistas no muestran ningún respeto por el idioma auténtico, el que habla el autor:

[...] de su discurrir puede sacarse una consecuencia preocupadora: la falta de respeto de algunos periodistas por casi todo. En un semanario madrileño mutilaron mi respuesta a la pregunta que me hicieron [...] y entrecomillaron la palabra culebrón, como si fuera un extranjerismo o una voz de jerigonza, ignorando que es español castizo y que significa lo que quise decir, o sea telenovela de acentuado carácter melodramático. (Cela, ABC, 17 de septiembre de 1994; las cursivas son nuestras)

Es por esta falta de responsabilidad de los hablantes que se hace necesario legislar, planificar para proteger el idioma de la invasión extranjera:

El proyecto de ley elaborado por los franceses se enfrenta valerosamente con el posible deterioro de su lengua y dicta las normas sobre su uso y el de las demás lenguas en lid; declara obligatoria la utilización del francés en las relaciones laborales [...] lo reglamenta en la radio y la televisión y prohíbe los términos extranjeros en cualquier lugar o transporte público. ¿Por qué no hacemos algo por el estilo los españoles, a quienes parece que nos da vergüenza hablar español? (Cela, ABC, 11 de marzo de 1994)

Por lo tanto, ¿qué idea de lengua tiene Camilo José Cela? Creemos que poco tiene que ver con una lectura del español como punto de encuentro y sí con una lectura del idioma cercana a un normativismo casticista con una fuerte atención a la lengua escrita, que aún mantiene una cierta vigencia en nuestros días. Es posible relacionar la idea de la lengua de Cela con una tradición purista de corte 
defensivo cuyos orígenes se remontan a la llustración y que nace como reacción a las altisonancias barrocas y a la irrupción de los galicismos (v. Lázaro Carreter, 1985: 280 y ss.; Lara, 2005: 177-178). Se trataría de un purismo fuertemente hostil a la entrada de elementos extranjeros en la lengua que, sin embargo, en lo que a niveles de estilo (v. Ludwig, 2000: 178) se refiere, es muy tolerante con respecto a la presencia de los dialectalismos (Ludwig, 2000: 188). Y esta lengua "eficaz y gloriosa" - tan cercana a la de Menéndez Pidal - se nos presentará siempre bajo la sempiterna amenaza del inglés, como en el pasado lo había estado bajo la del francés (Lara, 2007: 175-177).

Y, ¿cuál será la condena a aquellos que no respeten la pureza de la lengua, a los que contaminen su identidad? La respuesta nos la da en "El juego de las renuncias y las abdicaciones". Es la cursilería: "Lo digo por casi todos los españoles, omisión hecha de su clase social, su naturaleza local o su ubicación regional, que la cursilería se salta todas la barreras" (Cela, ABC, 21 de julio de 1996). Y su definición creemos que se aproxima mucho al planteamiento que hace Ramón Gómez de la Serna y que recoge Francisco Umbral (1996, 103-105): necesidad de que la mediocridad de la vida cotidiana sea trascendida o prevaricada, el intento de ocultar las aristas de la realidad bajo un manto de suave falsedad. Lo cursi será equiparado al supuesto aplanamiento de la sociedad contemporánea: "Y lo que dicen y lo que piensan no varía casi nada de unos a otros, la verdad es que los raptos de afán igualador, o igualatorio o igualitario, dígalo y óigalo como quiera, que es todo lo mismo, resultan muy tímidamente y escasamente originales" (Cela, $A B C, 21$ de julio de 1996). Por todo esto, el otro campo de batalla del escritor se encontrará en los dominios del eufemismo y de la llamada "corrección política" que servirá, por un lado, para cubrir con un tupido velo las miserias de la sociedad: "A los viejos, primero se les humilla convenciéndoles de que su estado se llama la tercera edad y después se les encierra en un asilo al que eufemísticamente se designa como residencia, donde se les subalimenta con pienso para perros y se les condena a morir de soledad" (Cela, ABC, $1^{\circ}$ de diciembre de 1995).

Y, como es previsible, por otro, creará problemas donde no los hay. Como podría ser, por ejemplo, dejar de lado prioridades más importantes y dedicarse a cambiar nombres perfectamente funcionales a ciertos colectivos porque podrían resultar ofensivos. Entre los muchos ejemplos que tenemos a disposición, elegimos este:

Roque Sanz Sarmiento, alias Feldespato, amén de ser duro de gorra y profesor de ping-pong, es un pardillo consecuente y un hombre de costumbres prescritas, y esto se paga a muy alto precio porque lo políticamente correcto no es enseñar a saludar al prójimo sino solidarizarse con los zurrados y no llamar jamás negro al negro; con esto ya se cumple y el que venga detrás, que arree. (Cela, $A B C, 27$ de diciembre de 1998)

Deborah Cameron señala que la motivación que subyace a las críticas de la llamada "corrección política" reside - y en este caso será así - en el hecho de que demuestran que el lenguaje no es solo un medio neutral de comunicación de ideas, que no debe ser tocado so pena de destruir un patrimonio amasado durante siglos de historia, sino que sirve para dar forma a esas ideas, que la elección de una palabra u otra es una toma de posición en la que la pregunta no es tanto sobre la legitimidad 
del lenguaje sino sobre la legitimidad del conjunto de valores que se transmiten a través del mismo y sobre quién tiene que decidirlo (Cameron, 2012, cap. 4).

Todo esto nos lleva a situar a Cela cerca de los orígenes de un conservadurismo que consiste en un humanismo centrado no en la defensa de los derechos fundamentales sino en los valores, caracteres y situaciones que identifican socialmente al hombre (v. Herrero de Miñón, 2008: 281-287). De ahí que sea necesaria la caracterización objetiva de un pueblo entendido como comunidad que se sostiene sobre una serie de vínculos abstractos: religión, historia compartida o lengua. Y que estos valores se nos muestren inmóviles, pétreos, sin posibilidad de dinamismo. Por eso, más que asociar a Cela a un movimiento nacionalista abierto a la creación de valores nuevos, vemos una especie de inmovilidad que se podría relacionar con el tradicionalismo de ciertas corrientes de las derechas autoritarias que confluyeron en la dictadura franquista (González Cuevas, 2000: 390-398), y que fueron víctimas de lo que Staal (1987) Ilama "la ironía del moderno conservadurismo": la promoción del desarrollo socioeconómico acabó por socavar los valores sobre los que se sostenía y por hacerle perder toda legitimidad (v. González Cuevas, 2009: 400-404). Como podemos ver, las medidas de higiene verbal que plantea Camilo José Cela, en consonancia con las afirmaciones de Deborah Cameron (2012, cap. 1) cuando analiza el fenómeno, responden sobre todo a razones extralingüísticas.

\section{La imperial eñe}

¿Cómo encajar sin que chirríe esta interpretación a la vez frágil y gloriosa del idioma con la situación plurilingüe de España? Quizá la reflexión sobre el bilingüismo que se incluye en los últimos compases del libro Viaje al Pirineo de Lérida nos pueda servir como punto de partida:

Por todos estos pueblos se sigue hablando el catalán: mejor o peor, ya que, en estas zonas de fricción de lenguas, las lenguas se despedazan - o se liman - al convivir o influirse recíprocamente. El fenómeno del bilingüismo - a lo que el viajero arbitra en sus soliloquio - suele caracterizarse más por el aproximado conocimiento de dos lenguas que por el puntual uso de una de ellas; [...] con él [el bilingüismo] sufren - que no gozan - las dos lenguas, quienes, en su estéril dolor, engendran monstruos. (Cela, 2010)

Del Valle, al analizar la cultura lingüística del nacionalismo en España, plantea como uno de sus principios fundamentales el de focalización. Es decir, la necesidad de que los hablantes utilicen un sistema lo más definido posible y, sobre todo, que sea permeable a muy pocas variaciones ya que se parte de la idea de que una comunidad lingüística debe caracterizarse por la homogeneidad (Del Valle, 2004c). En este sentido, los comportamientos típicos de zonas heteroglósicas quedan estigmatizados, como ocurre en este caso, al poner en discusión el principio de que una comunidad es igual a una lengua. 
Posteriormente, Cela defiende la necesidad de enseñar el catalán a sus hablantes con el objetivo de que puedan "hablar mejor el castellano" (Cela, 2010) ya que "es la lengua que los españoles no castellanos - que formamos legión y somos mayoría - admitimos como común y apta y suficiente para entendernos entre todos" (Cela, 2010). Es decir, la ventaja del castellano con respecto a las demás lenguas del espacio plurilingüe de la Península Ibérica sería que es el idioma común. Ahora bien, lo que se elide cuidadosamente es lo que señala Ángel López García: el español es como una moneda con dos caras. Una sería la de su condición de lengua común desde la Edad Media y la otra, su oficialidad desde el s. XVIII (López García, 2009: 70-74; v. Del Valle, 2007b: 90-92). Oficialidad esta que ha añadido un factor emotivo mucho más peligroso que el estatus legal de la lengua. El paso de la aceptación del español como instrumento de comunicación a su imposición por vías legales ha traído como consecuencia, por un lado, su rechazo en las zonas bilingües, y, por otro, el rechazo de las lenguas cooficiales por parte de los hispanohablantes que leen en sus agresivas políticas de recuperación también una imposición. Digamos que esta lealtad por la lengua común como forma de vínculo afectivo que une a los miembros de una comunidad imaginada queda en entredicho. El conflicto de la oficialidad, muy presente en los tiempos de la dictadura, cuando se escribe este artículo, se obvia.

Por todo esto, en este nuevo contexto, la defensa de la lengua española se realizará de acuerdo con un modelo lingüístico de corte racionalista (Geeraerts, 2008: 46-51) en el que el lenguaje ya no es tanto la expresión de valores, sino un medio de comunicación deslocalizado que sirve para facilitar la comunicación y la transmisión de la cultura. Es por ello que un artículo de diez años después, "El elogio del castellano", que en gran parte es una reproducción de este texto, Cela asevere que "en una vista que hice a mi amigo Josep Pla en Palafagruell, le hice notar el suceso - que en ningún caso debe atribuirse a la casualidad - de que él, catalán, y yo, gallego, manteníamos la conversación en castellano: la lengua que nos era común" (Cela, 1990: 256). En este mismo artículo y, en contradicción con gran parte de los posteriores artículos de opinión de "El color de la mañana" y los discursos en los Congresos de la Lengua, el autor defiende la denominación de "castellano" en vez de "español" porque de esta forma se pregona "lo que menos importa de ella [la lengua], su carácter oficial. Es decir, se intentan separar, de forma poco afortunada, ya que una cosa es condición de la otra, esa oficialidad política del idioma de su condición de medio de transmisión de la cultura" (Cela, 1990).

Kathryn Woolard plantea el concepto de ideología del anonimato como un medio para justificar la imposición de lenguas "comunes" a hablantes de lenguas minoritarias (Woolard, 2007: 133 y ss.). Esta lengua serviría como patrimonio que permitiría a sus hablantes la participación en el discurso público de una comunidad, independientemente de cuál sea su lengua materna. Esta premisa y el argumento emotivo planteado nos permiten entender mejor la agria crítica que realiza Camilo José Cela, ya en 1994, al uso de la traducción simultánea en el Parlamento de España, la cual, para el autor, sería "hacer el mal por necedad" (Cela, ABC, 9 de octubre de 1994). Para argumentar su opinión, Cela utiliza el argumento por ridículo (Santamaría y Casals, 2000: 249-252) y opta por la reducción al absurdo: 
Una vecina mía, doña Fidela Muriedas, viuda de Méndez Alcolea, me dijo anoche que menos mal que no habían ido los vascos y que los presidentes de las Comunidades de Asturias, Murcia, Extremadura, Valencia, Baleares, Andalucía y Canarias habían renunciado a expresarse en bable, panocho, castrúo o chinato, a elegir, chelí, valenciano, mallorquín o menorquín o ibicenco, según la insularidad, romanó, por eso de la abundancia de gitanos, y guanche, lengua a la que, aunque muerta desde el siglo XIV, siempre podrá resucitarla cualquier patriota medianamente aplicado. (Cela, ABC, 9 de octubre de 1994)

Como podemos ver, la larga enumeración de regiones y lenguas produce en el lector una sensación de caos babélico, en el que cualquier comunicación y, por ende, comunión se hace materialmente imposible. No debemos olvidar que uno de los conceptos fundamentales de la ideología nacionalista es la existencia de una cultura pública (Smith, 2010) capaz de definir a la nación, que en este caso sería una especie de cultura cívica cuyo cauce es el idioma necesario para la convivencia. Así, es normal que, al final del artículo, se produzca el siguiente diálogo:

- Oiga, doña Fidela, dicho sea tras pedirle perdón por la licencia de mi pregunta, ¿usted sería capaz de acostarse con alguien con quien, para entenderse, necesitase de la traducción simultánea?

- ¡Quite usted allá, hombre, quite usted allá! ¡Antes lo hubiera preferido mudo! (Cela, ABC, 9 de octubre de 1994)

Quizás esta metáfora sexual nos pueda dar idea en gran medida de cómo el nacionalismo inventa la comunidad: una especie de fraternidad en la que se obvia cualquier relación de dominio subyacente. Y esta comunidad solo será posible si es homogénea, si existe una lengua común. En defensa de esta unidad nacional, las críticas del autor se extenderán a los cambios en la toponomástica nacional, que serán vistos, de nuevo, como una amenaza a la unidad. Este texto es interesante porque considera que estos cambios responden a una voluntad política, que se nos presenta como ajena a la realidad de los habitantes de la nación:

Quienes creen que las lenguas se pueden gobernar por decreto, que suelen ser curas rebotados, forasteros conversos y patriotas a la violeta con aficiones léxicas adobadas con el salmorejo del arbitrista, quieren llamarle A Coruña, con la complicidad de la guía de la Telefónica que, olvidando la norma elemental de no alfabetizar el artículo, coloca a La Coruña, convertida en A Coruña, en el primer lugar de la nómina de las provincias españolas. (Cela, 16 de junio de 1995)

Se trata de un intento de universalizar una ideología al presentar el cambio toponomástico, como antes ocurría en el comentario sobre la traducción simultánea, como un atentado al sentido común²:

3. Que en este caso serían presupuestos ideológicos tan hegemónicos que pasan a ser inconscientes, que su veracidad no se pone en duda porque no hay alternativas (v. Van Dijk, 2005: 133-140). 
un pueblo debe ser un solo idioma. En la posterior argumentación, Cela vuelve a recurrir al argumento del ridículo a través de la reducción al absurdo. Sin embargo, en esta argumentación hay un detalle que llama la atención: "¿Por qué, resucitando viejas pretensiones hoy prescritas, no se habla de A Cruña? ¿Por qué, complaciendo a los lusistas, no se escribe A Crunha, con lo que se desplaza a la imperial eñe, que es el más evidente signo de modernidad de todos los alfabetos occidentales?" (Cela, 16 de junio de 1995).

Camilo José Cela se hace eco, de nuevo, de otro de los mitos lingüísticos del español. La defensa de la letra ñ como, en palabras de Gregorio Salvador en su Historia de las letras, "la aportación española al alfabeto latino. [...] [L] a simple duda acerca de su carácter de letra independiente ya es ofensa que se le hace a la cultura hispánica" (Salvador y Lodares, 2008: 56). Esta letra, que se identificaría con el Imperio, ha sido considerada por otros miembros de la Academia como José María Ansón como una especie de demostración de la superioridad cultural de los hablantes de español con respecto a los de otras lenguas neolatinas entre las que, obviamente, se incluyen las habladas en el territorio de la nación:

Franceses e italianos, para conseguir el sonido de la ñ tienen que escribir gn; los portugueses, nh. Los españoles, como ha escrito Gregorio Salvador, hicieron en el castellano - no así en el catalán - la gran aportación al descubrir por vía lúdica la diferencia fonológica entre una nasal alveolar - la n - y una nasal palatal - la ñ -. (Ansón, 24 de mayo de 2013)

Lo que más nos interesa, de nuevo, es la presentación de esta letra como obra de una colectividad que se identifica en su lengua y que, por ello, es superior a las demás. Obviamente, en nuestro corpus, no podría faltar el paso siguiente: los hablantes de las otras lenguas peninsulares se nos presentarán ridiculizados a través del uso y deformación de estereotipos culturales:

Baltzuskie se entrenó reventando latas de refresco por el mismo sistema [el uso del ano] y cuando ya se sintió seguro, se fue contra las nueces y no dejó ni una. Además accedió al libro de los récords, al Guiness, con toda justicia, y de paso, le ganó una apuesta de cinco mil duros a su alcalde, que dudaba de las recias habilidades de su salvohonor euscaldún.

¡Gora ipurtaldea euskaldun! ¡Viva el culo vasco! (Cela, ABC, 28 de mayo de 1994)

\section{Espigaruela y yuyarita}

En Cela también hay un amor por las palabras que se concreta en su larga trayectoria como lexicógrafo y en el uso continuo en su obra literaria de arcaísmos, regionalismos, jergas y creaciones neológicas hasta el punto de conseguir la recreación personalísima de una variedad latinoamericana, como ocurre en La Catira (v. Suárez Solís, 1969), hechos estos que hacen que Soldevila Durante (1990: 109) lo califique como "coleccionista de palabras". ¿Qué actitud tiene el autor ante el caudal léxico del español? Si nos olvidamos de los préstamos extranjeros, ¿qué palabras deberían ser admi- 
tidas en los diccionarios? Quizás este fragmento del preámbulo de su Diccionario secreto nos pueda resumir bien su punto de vista:

El hecho de que una palabra exista no lleva aparejada la suposición de que su empleo sea o deje de ser preconizable sino, simplemente, indica la evidencia de que existe como tal palabra, esto es: que está ahí, cumpliendo una función - nombrando un objeto, una acción, una sensación o matizando sus cualidades - pero manteniéndose, en sí misma, al margen de las consideraciones de su significado - y con frecuencia, no más que su convencional y pura disonancia - pudieran levantar a su paso. (Cela, 1970: 23)

Si partimos de la consideración del diccionario no como una lista despersonalizada de palabras sino como un objeto cultural portador de una interpretación interesada del mundo (Pérez, 2000: 11-35; Pérez, 2005), quizá podamos entender mejor la postura de Camilo José Cela con respecto al lenguaje. Desde nuestro punto de vista, para Cela, las palabras no están legitimadas para entrar en el diccionario solamente por su existencia, tal y como parece decir en la cita anterior. Más bien, lo están por una historia y por su correspondencia con un hipotético "espíritu de la lengua" que la mantiene viva. Y con estos criterios el autor cifró su "cruzada" lexicográfica: la inclusión del vocabulario marcado en el diccionario por el solo hecho de ser patrimonial. Así interpreta nuestro autor en 1979 la nueva entrada de la palabra cojón en el Diccionario de la Real Academia:

Numerosas palabras que siempre tuvieron asiento en el diccionario - ¿para qué repetirlas ahora? - no son pronunciadas jamás en la conversación mantenida entre personas que, por las razones que fueren - y todas para mí son lícitas y respetuosas - prefieren callarlas. Pero, por el contrario camino, negar lo obvio y rechazar lo vivo y latidor, es pecado que suele pagarse con muy dura penitencia: la de que el hablante vuelva la espalda a la Academia [...]. (Cela, 1990: 334)

El criterio de Cela a la hora de seleccionar qué puede pertenecer a nuestro idioma y qué no tendrá mucho que ver con el concepto romántico de "forma interior de la lengua", acuñado por Humboldty que, en su suma vaguedad, sirve para describir el lenguaje solo con la ayuda de la intuición (Moreno Cabrera, 2008: 186-191). Intuiciones estas que se disfrazarán de cientificidad, tal y como demuestra Moreno Cabrera al analizar la tradición filológica del español. En estos artículos, esta "forma interior" aparecerá con las vestiduras de "espíritu de la lengua" o "realidad de la lengua" y su entidad será, como mínimo, nebulosa:

Hace cosa de una semana y sin comerlo ni beberlo me vi envuelto en un alarmante aluvión de palabras mansas, domésticas y municipales que me dieron mucho que pensar y que aburrir: marcapasos, videoconsola, lavavajillas [...]; todas van contra el espíritu de la lengua, y algunas figuran ya registradas en el diccionario de la Real Academia, situación más triste que preocupadora y menos alarmante que ridícula. (Cela, ABC, 7 de febrero de 1999) 
De acuerdo con lo que hemos dicho antes, lo más llamativo del texto es esta aversión por la composición para crear nuevas palabras que se utilizan simplemente para nombrar realidades que no existían en el pasado. Del artículo también se deduce que el espíritu de la lengua se cifra sobre todo en las sensaciones que produce el sonido: "los hombres, aun los que menos histéricos pudiéramos parecer, somos muy sensibles a los decorados y a los parlamentos y no tenemos la misma tensión arterial en unos que en otros; las palabras pueden ser calmantes, es cierto, pero también excitantes y sobresaltadoras" (Cela, ABC, 7 de febrero de 1999). Las palabras que se merecen perdurar son aquellas que nos pueden "despertar" con su sonido, con su voz. El artículo termina, de nuevo, con una asociación icónica entre palabra y realidad extralingüística: "Hace muy pocos días me quemé la mano porque la puse al fuego en defensa del caprichoso supuesto de que el marcapasos era arbitrio propio de maricones. No hay soberbia que no caiga" (Cela, ABC, 7 de febrero de 1999). Es por eso que, en otro artículo, la falta de respeto por este "espíritu de la lengua" será causa final de la ya citada cursilería entendida como degeneración de la sociedad:

Hay que acostumbrarse a precisar y cuando los humanistas os hablen del espíritu de la lengua, hacedles un corte de mangas aunque no sea más que con la intención. Hay que acostumbrarse a precisar, mis queridas amigas, y si decimos azucarar cuando nos referimos al café del desayuno, ¿por qué no hemos de dar cabida al bello verbo azucarinizar cuando aludimos a un exquisito poirier d'Anjou? (Cela, ABC, 21 de octubre de 1996)

Esta persecución intuitiva del espíritu de la lengua tiene también su reflejo en uno de los juegos literarios preferidos de Camilo José Cela: la creación léxica. Como indica Soldevila Durante (1990), el papel que Cela aceptó para hacer un cameo en la adaptación cinematográfica de La Colmena fue precisamente el del inventor de palabras Matías Martí. Sin embargo, en el análisis de su obra se observa una gran prudencia a la hora de crear palabras nuevas que contrasta con una ingente labor de consulta de fuentes lexicográficas. En el artículo "Palabras poco conocidas" Cela nos propone una lista de palabras que si bien se nos dice que existen, no figuran en los diccionarios. Veamos una serie de ejemplos:

azuvel. Planta herbácea de la familia de las umbelíferas, con tallos erguidos y estriados de un palmo de altura; hojas partidas en numerosas lacinias filiformes, flores de azul cobalto y fruto oblongo que encierra numerosas semillas. Flor de dicha planta [...]

espigaruela. Cáncer de útero. [...]

yuyarita. Enfermedad psíquica febril producida por un determinado protozoo y transmitida al hombre por el canto de los grillos. [...]

zangazón. Cáncer de próstata. (Cela, ABC, 12 de mayo de 1994)

Detrás de lo que parece una simple diversión lingüística, hay una posible definición de la naturaleza del idioma español. Cela practica la neología formal a través de la creación de una serie de significantes ex nihilo (Guerrero Ramos, 2010: 24 y ss.) que imitan la etimología árabe (azuvel, que 
se nos presenta como si fuera una palabra derivada de azul, cuya probable etimología es el árabe hispánico lazawárd), la de lenguas amerindias (yuyarita, tan cercana a yuyo, palabra de origen quechua recogida en el DRAE cuya primera acepción es "mala hierba") o copian onomatopeyas para nombrar insectos (zangazón). Asimismo, también observamos palabras creadas por una derivación que difícilmente podría motivarse con el significado asignado (espigaruela). Es decir, vista la opacidad de los significantes, la "españolidad" de las palabras residirá en su sonoridad o en la imitación de una posible etimología. Y en el efecto que causen en el lector cuando se vea obligado a buscar una posible motivación entre significante y significado. Particularmente interesante es este juego en el siguiente fragmento: la combinación entre palabras patrimoniales y los neologismos del idiolecto celiano (praxia, azuvel, simbelia, urolea, taragona, lascarita) crea un hermoso efecto estético a través de la aliteración. El lector tiene la sensación de que existe una relación de motivación entre la belleza de unas flores que no existen y los nombres que les ha otorgado el escritor:

Uno quisiera inventar un abecedario bellísimo y de color de flor, de colores de flores, rojo de rosa tersa o de amapola áspera, anaranjado de dalia o de unrolea, amarillo de botón de oro, verde de simbelia o de taragona, azul de lascarita o de azuvel, índigo de praxia silverstre y violeta de violeta mansa [...]. (Cela, ABC, 21 de abril de 1994)

Dicho esto, no es sorprendente que Cela dé el siguiente paso: también el léxico aceptado por el escritor por su patrimonialidad, pero rechazado por los lexicógrafos se nos presentará iconizado, asociado a una realidad extralingüística positiva dentro de la cosmovisión del escritor. En este caso, la palabra chusquero se relaciona con la vida aventurera del general Camilo García de Polavieja, arquetipo del hombre de acción que, como es común en la obra de Camilo José Cela, se opone al hombre de ideas apático, una especie de parásito incapaz de construir nada con sus propias manos (v. Regueiro, 2009: 183-185):

[...] a quienes llegan paso a paso y desde abajo del todo, se les suele llamar chusqueros o patateros; me contó mi también colombroño don Camilo el del premio, bueno el de los premios, que en la Real Academia Española tuvieron que esperar a que se muriese el duque de la Torre, a quienes todos los académicos querían y respetaban, para poder dejar tranquilas a esas dos palabras en el diccionario, bien entendido que la presencia en él de una voz evidente y usual, por tosca que nos pareciere, en ningún caso significa aplauso, sino mera constatación de su existencia. [...]

A mí, estos hombres que se pasaron la vida haciendo cosas y sin darse un punto de sosiego siempre me llamaron la atención, me despertaron admiración y hasta me inspiraron veneración. [...] Hoy, la gente propende a la holganza y a que le den todo masticado y, a ser posible, hasta rumiado y digerido, y eso agosta los temples y las voluntades, y acaba vaciando de sentido común la sociedad entera. (Cela, ABC, 18 de febrero de 1996) 


\section{Escritores y magos}

Para terminar, una vez que hemos definido el concepto de lengua que defiende Camilo José Cela, sus métodos para caracterizarla y parte de los enemigos que la amenazan, se hace necesario saber quién debe ser el responsable de su defensa. Ya hemos adelantado algo sobre las diferencias de Cela con los lexicógrafos. Y es que en el escritor no hay dudas: son los mismos creadores quienes deben ocuparse de su respeto, ya que poseen una intuición para captar su espíritu que queda fuera del alcance de los lingüistas, que serán además, en cierto sentido, también responsables de su decadencia:
Los escritores - y Unamuno lo fue antes que ninguna otra cosa - adivinan la lengua, la am- plían, la precisan y la flexibilizan, mientras que los glosadores que se deberían limitar a estu- diarla propenden, en su administrativa soberbia, a invadir órbitas ajenas y muy peculiares. En esta permanente fricción ha de rastrearse el origen del creciente deterioro de la lengua en el que inciden, con un entusiasmo digno de la mejor causa, quienes carecen de su sentido, esto es, los pretenciosos funcionarios que confunden la ciencia y el arte con su vinculación con el presupuesto, esa forma de parasitismo deformante. (Cela, ABC, 18 de enero de 1998)

Quizás a este planteamiento del escritor como responsable del "desarrollo" del idioma subyace una ya clásica lectura de la lengua literaria como desviación con respecto a una lengua estándar fija (v. Mukarovsky, 2000: 227-228); para Cela, esta desviación tendría mucho de lectura iluminada del idioma y traería como consecuencia un necesario enriquecimiento del estándar. Ahora bien, el responsable exclusivo de este dinamismo sería el escritor. Los lingüistas no serían capaces de adivinar la naturaleza del idioma porque esto exige una serie de capacidades que poco que tienen que ver con la razón y mucho con la intuición. Mejor dicho, casi con la práctica de las artes mágicas:

Siempre pensé que un pujante y sabio colegio de lexicografía debería funcionar, con todos los honores y consideraciones a la sombra y servicio de la Academia - y de la lengua, claro es - y siempre supuse que esa precaución alejaría el peligro de convertir a la Academia en el Inserso de la Universidad o de ahogarla en unas complejas técnicas que le son ajenas; la misteriosa sabiduría de los lexicógrafos suele llevarlos por senderos muy diferentes de lo que pudiéramos llamar el espíritu de la lengua y su adivinación, habilidad mágica que tienen los poetas y, en cierto sentido, también los campesinos. (Cela, ABC, 17 de enero de 1999; las cursivas son nuestras)

Se trata de una cuestión de gran complejidad, ya que, como señala Sylvia Adamson (2007) para el caso del inglés, la codificación del lenguaje estándar y la canonización de textos literarios serían dos procesos que no se desarrollan de forma paralela, sino que se establece una relación simbiótica entre ambos, de tal manera que los escritores muchas veces acaban por convertirse en símbolos de una cierta variedad que los lingüistas plantean como estándar, y sus escritos, en muestras de 
buen uso (v. Beaumer y Scaglione, 1984: 13 y ss). En este caso, Cela estaría reivindicando de nuevo la legitimidad exclusiva del creador.

Pierre Bourdieu (2001) nos plantea una concepción del lenguaje entendido como instrumento de acción y poder, expresión de un orden que busca la aceptación de las desigualdades sociales de las que es reflejo. La comunicación, entonces, no se daría en condiciones de libre intercambio sino en un contexto condicionado por aquellos que detentan un determinado poder en un mercado lingüístico ${ }^{4}$. Este mercado conformaría el campo de la interacción entre diferentes grupos con diferentes competencias en el que se harían valer capitales lingüísticos y simbólicos provenientes de posiciones consolidadas. En la lucha por el monopolio de la lengua legítima, nos resulta de particular interés la pugna que se da entre lingüistas y miembros del campo literario a la hora de decidir las características de un discurso digno de ser publicado (Bourdieu, 2001: 32). Los escritores a pesar de luchar por la configuración de la lengua legítima acaban porverse obligados a contar con los gramáticos - auténticos juristas de la lengua - en cuanto que los últimos consagran de forma razonada usos particulares. En el caso de Camilo José Cela, la rebelión del escritor con respecto al lingüista respondería a una invariante estructural del campo lingüístico que el mismo Bourdieu resume así:

Frente al "uso elegante" de los mundanos y la pretensión de los escritores de poseer la ciencia infusa del buen uso, los gramáticos invocan siempre el uso razonado, es decir, el sentido de la lengua que confiere el conocimiento de los principios de "razón" y de "gusto" constitutivos de la gramática. En cuanto a los escritores, cuyas pretensiones se afirman sobre todo en el romanticismo, invocan el genio contra la regla, haciendo profesión de fe de ignorar las llamadas al orden de quienes Hugo llamaba altivamente los "gramatistas". (Bourdieu, 2001: 33)

¿Y qué significado tendrá ser escritor para Camilo José Cela? ¿Quién podrá tener derecho al poder de consagración? En este sentido, la semblanza que hace Cela de Francisco Umbral, en el contexto del rechazo de su candidatura a la Real Academia es reveladora:

Ahora, los escritores blasonan de mansedumbre, aspiran al funcionariado, opositan al aburrimiento, sonríen al administrador, prestan oídos a la consigna, copian al extranjero y sueñan con subsistir de los benévolos y casi nutricios flecos del Estado del Bienestar; pero hubo un tiempo todavía no demasiado lejano en el que eran tenidos por herejes y asilados como leprosos, en el que luchaban contra la censura y la entera y siempre mediocre sociedad [...]. (Cela, $A B C, 2$ de febrero de 1995)

Nos encontramos con ese escritor perteneciente a un campo literario cuya illusio se cifra en una siempre imposible autonomía total con respecto a los demás campos sociales que persigue, como señala Bourdieu en Las reglas del arte (1995: 321 y ss), la obtención de un capital simbólico - que

4. O una situación social más o menos establecida donde un hablante produce un discurso que unos receptores podrán evaluar y dar un precio. Este mercado poseerá leyes de determinación que harán que todos los productos que entren no sean iguales. 
le permita decidir sobre la lengua legítima, añadiríamos - y no económico. El mismo Bourdieu lo sitúa en la lógica "del que pierde, gana" (Bourdieu, 1990: 16-17). Gana a través del rechazo de las condiciones del poder y de la autoridad cultural dicho capital simbólico en detrimento de otros beneficios, como es la aceptación entre las autoridades lingüísticas. Cela profundiza en esta idea al reflexionar sobre la definición del escritor en un artículo curiosamente dedicado a un lingüista, Rafael Lapesa. Así, las distinciones, los reconocimientos, las responsabilidades con respecto al idioma deberían estar reservadas "no más que a los amigos de las musas, a los angelicales y malditos, a los atormentados y obnubilados amaestradores de palabras que van de musas como otros, los glosadores y divulgadores, pongamos por caso, van de putas" (Cela, ABC, 19 de enero de 1997). La conclusión es palmaria:

Supongo que a la Academia no le vendrá mal volver la al cultivo de la materia prima, después de tantos años de adorar el santo por la peana, de idealizar siempre al confuso glosador en detrimento de la madre y el padre del cordero de la literatura y de la lengua, y de confundir al tafanario con los cuatro tiempos del ayuno debido. (Cela, ABC, 20 de junio de 1995)

\section{Conclusión}

Cela se ha movido siempre dentro de las coordenadas de una ideología lingüística nacionalista que se presenta como ideología de la autenticidad o del anonimato según cuál sea el enemigo a batir. Esta pervivencia arcaica - un tanto discordante con los procesos que se daban durante la modernización del país durante los años noventa - nos plantea la lengua como un conjunto de esencias que sirven para dar forma a la identidad de un pueblo. Y esta identidad debe ser protegida por una serie de sacerdotes elegidos por su talento y por su conocimiento: los escritores. Todo ello creemos que enlaza con la voluntad antimoderna y antieuropea que hay en estos artículos. 


\section{Bibliografía}

\section{Fuentes primarias}

Corpus de 412 artículos de opinión publicados en $A B C$ bajo el epígrafe "El color de la mañana" entre el 21 de noviembre de 1993 y el 13 de enero de 2002.

\section{Artículos citados}

Cela, Camilo José (1993), "Con la venia”, ABC, 21 de noviembre, p. 21.

Cela, Camilo José (1994), "Nuestros vecinos los franceses”, ABC, 11 de marzo, p. 15.

Cela, Camilo José (1994), "Teoría de la letra (III)”, ABC, 21 de abril, p. 15.

Cela, Camilo José (1994), “Palabras poco conocidas”, ABC, 12 de mayo, p. 19.

Cela, Camilo José (1994), “¡Gora Ipurtaldea Euskaldun!”, ABC, 28 de mayo, p. 17.

Cela, Camilo José (1994), “STRC PRST SKRZ KRK”, ABC, 26 de junio, p. 17.

Cela, Camilo José (1994), "Palabras para un pescador de caña”, ABC, 9 de julio, p. 19.

Cela, Camilo José (1994), "Recuerdo de tres amigas”, ABC, 9 de septiembre, p. 13.

Cela, Camilo José (1994), “Falta de respeto”, ABC, 17 de septiembre, p. 15.

Cela, Camilo José (1994), "La escala de la necedad”, ABC, 9 de octubre, p. 19.

Cela, Camilo José (1994), “Matías y Eulogio, o sea, Fred y Ted”, ABC, 16 de diciembre, p. 13.

Cela, Camilo José (1995), "Insistiending”, ABC, 3 de enero, p. 11.

Cela, Camilo José (1995), "Paco”, ABC, 2 de febrero, p. 15.

Cela, Camilo José (1995), “Trascendente problema político”, ABC, 16 de junio, p. 31.

Cela, Camilo José (1995), “Arrabal, Bonald, Umbral”, ABC, 20 de junio, p. 13.

Cela, Camilo José (1995), “Palabras para un pescador de caña”, ABC, 9 de julio, p. 19.

Cela, Camilo José (1995), "Sueños de juventud”, ABC, 22 de octubre, p. 15.

Cela, Camilo José (1995), "Otra historia triste”, ABC, $1^{\circ}$ de diciembre, p. 13.

Cela, Camilo José (1996), "Parábola del murciélago añorante”, ABC, 18 de febrero, p. 17.

Cela, Camilo José (1996), "El juego de las renuncias y las abdicaciones”, ABC, 21 de julio, p. 13.

Cela, Camilo José (1997), "Fronteras del oficio, ABC, 19 de enero, p. 19. 
Cela, Camilo José (1998), "Zapatero a tus zapatos o parábola de la cabeza, el corazón y la mano”, ABC, 18 de enero, p. 19.

Cela, Camilo José (1998), "Tokío, con acento en la i”, ABC, 5 de abril, p. 19.

Cela, Camilo José (1998), "El duro de gorra”, ABC, 27 de diciembre, p. 15.

Cela, Camilo José (1999), “Limpia, fija y da esplendor”, ABC, 17 de enero, p. 15.

Cela, Camilo José (1999), "Escala de valores”, ABC, 7 de febrero, p. 15.

Otras obras de Camilo José Cela

Cela, Camilo José (1970), Diccionario secreto. 1, Barcelona, Alfaguara.

Cela, Camilo José (1990), Obras completas. 23: La bola del mundo-Los sueños vanos, los ángeles curiosos, Barcelona, Destino.

Cela, Camilo José (2001), "Aviso de la defensa del español" [Discurso pronunciado en la Inauguración del II Congreso Internacional de la Lengua Española], disponible en http://cvc.cervantes.es/literatura/escritores/cela/discursos/default.htm. [Sitio consultado el 15 de marzo de 2014.]

Cela, Camilo José (2010), Viaje al Pirineo de Lérida, Pamplona, Leer-e. [1ªd., 1965.]

\section{Fuentes secundarias}

Adamson, Sylvia (2007), "Literary language”, en Suzanne Romaine (ed.), The Cambridge History of the English Language, Cambridge, Cambridge University Press, p. 589-687.

Alvar, Carlos, José-Carlos Mainer y Rosa Navarro (1997), Breve historia de la literatura española, Madrid, Alianza.

Anderson, Benedict (1993), Comunidades imaginadas: reflexiones sobre el origen y la difusión del nacionalismo, México D.F., Fondo de Cultura Económica. [Título original: Imagined Communities: Reflections on the Origin and the Spread of Nationalism, Londres/Nueva York, Verso. Traducción del inglés a cargo de Eduardo L. Suárez.]

Ansón, Luis María (2013), "La eñe desalmada”, El Cultural, 24 de mayo, disponible en http://www. elcultural.es/version_papel/OPINION/32848/La_ene_desalmada. [Sitio consultado el 15 de marzo de 2014.]

Beaumer, Max y Aldo Scaglione (1984), The Emergence of National Languages: Essays. Ravenna, Longo Editore.

Bourdieu, Pierre (1990), "El campo literario: prerrequisitos y principios de método", Criterios, n² 25-28, p. 20-42. [Título original: "Le champ littéraire: préalables critiques et principes de méthode", en Lendemains, n³6, 1984, p. 5-20. Traducción del francés a cargo de Desiderio Navarro.] 
Bourdieu, Pierre (1995), Las reglas del arte: génesis y estructura del campo literario, Barcelona, Anagrama. [Título original: Les règles de l'art: genèse et structure du champ littéraire, París, Editions du Seuil, 1992. Traducción del francés a cargo de Tomás Kauf.]

Bourdieu, Pierre (2001), ¿Qué significa hablar?, Madrid, Akal. [Título original: Ce que parler veut dire: l'économie des échanges linguistiques, París, Librairie Anthème Fayard, 1982. Traducción de Esperanza Martínez Pérez.]

Burke, Peter (2006), Lenguas y comunidades en la Europa moderna, Madrid, Akal. [Título original: Languages and Communities in Early Modern Age, Cambridge (Reino Unido), Cambridge University Press, 2004. Traducción del inglés a cargo de Jaime Blasco Castiñeyra.]

Cameron, Deborah (2012), Verbal Hygiene, Londres/Nueva York, Routledge. [1² ed., 1995.]

Del Valle, José (2000), "Monoglossic policies for a heteroglossic culture: Misinterpreted multilingualism in modern Galicia", Language and Communication, n² 20, p. 105-132.

Del Valle, José (2004), “Menéndez Pidal, national regeneration and the linguistic utopia”, en José Del Valle y Luis Gabriel-Stheeman (eds.), The battle over Spanish between 1800 and 2000, Londres/ Nueva York, Routledge, p. 78-105.

Del Valle, José (2007a), "Glotología, ideología y discurso: categorías para el estudio del estatus simbólico del español”, en José Del Valle (ed.), La lengua, ¿patria común? Ideas e ideologías del español, Madrid/Fráncfort, Iberoamericana/Vervuert, p. 13-30.

Del Valle, José (2007b), "La RAE y el español total: ¿esfera pública o comunidad discursiva?", en José Del Valle (ed.), La lengua, ¿patria común? Ideas e ideologías del español. Madrid/Fráncfort, Iberoamericana/Vervuert, p. 81-97.

Del Valle, José y Luis Gabriel-Stheeman (2004c), "Nationalism, hispanismo, and monoglossic culture", en José Del Valle y Luis Gabriel-Stheeman (eds.), The battle over Spanish between 1800 and 2000, Londres/Nueva York, Routledge, p. 1-13.

Edwards, John (2009), Language and Identity: An Introduction, Cambridge (Reino Unido), Cambridge University Press.

Gal, Susan (1998), "Multiplicity and Contention among Language Ideologies", en Bambi Schieffelin, Kathryn Woolard y Paul V. Kroskrity (eds.), Language Ideologies: Practice and Theory, Nueva York, Oxford University Press, p. 317-333

Geeraerts, Dick (2008), "The Logic of Language Models: Rationalist and Romantic Ideologies and their Avatars", en Kirsten Süselbeck, Ulrike Mülschlegel y Peter Masson (eds.), Lengua, Nación e Identidad: la regulación del plurilingüismo en España y América Latina, Madrid/Fráncfort, Iberoamericana/Vervuert, p. 43-74.

Gibson, Ian (2004), Cela, el hombre que quiso ganar, Madrid, Suma de Letras.

González Cuevas, Pedro Carlos (2000), Historia de las derechas españolas: de la Ilustración a nuestros días, Madrid, Biblioteca Nueva. 
Guerrero, Gustavo (2008), Historia de un encargo: La Catira de Camilo José Cela. Literatura, ideología y diplomacia en tiempos de la Hispanidad, Barcelona, Anagrama.

Guerrero Ramos, Gloria (2010), Neologismos en el español actual, Madrid, Arco-Libros. [1ªd., 1995.]

Hermida, Xosé (1998), “Cela critica la presencia de 'gay' en los homenajes a Lorca”, El País, 11 de junio, p. 15.

Herrero de Miñón, Miguel (2008), Tipología del pensamiento conservador, Madrid, Real Academia de Ciencias Morales y Políticas.

Lara, Luis Fernando (2005), "Por una reconstrucción de la idea de lengua española: más allá de las fronteras instituidas", Revista internacional de lingüística iberoamericana, vol. 3, n² 2 (6), p. 171 190.

Lara, Luis Fernando (2007), “Por una reconstrucción de la idea de lengua española”, en José Del Valle (ed.), La lengua, ¿patria común? Ideas e ideologías del español, Madrid/Frankfurt, Iberoamericana/Vervuert, p. 163-182.

Lázaro Carreter, Fernando (1985), Las ideas lingüísticas en España durante el siglo XVIII, Madrid, Crítica. [1 $1^{2}$ ed., 1949.]

León Gross, Teodoro (1996), El artículo de opinión, Barcelona, Ariel.

Lopatina, Ksenia (2011), "Los antropónimos en 'La Colmena' de C. J. Cela como prueba de la posición activa del narrador en una novela objetivista”, Estudios Humanísticos: filología, n 33, p. 275-282.

López García, Ángel (2009), La lengua común en la España plurilingüe, Madrid/Fráncfort, Iberoamericana/Vervuert.

López Pan, Fernando (1996), La columna periodística: teoría y práctica. El caso de Hilo Directo, Pamplona, EUNSA.

Ludwig, Ralph (2000), "Desde el contacto hacia el conflicto lingüístico: el purismo en el español. Concepto, desarrollo histórico y significación actual", Boletín de Filología, nº 38 (1), p. 167-196

Irvine, Judith T. y Susan Gal (2000), "Language Ideology and Linguistic Differentiation”, en Paul V. Kroskrity (ed.), Regimes of Language: Ideologies, Polities and Identities, Santa Fe, School of American Research Press, p. 35-84.

Menéndez Pidal, Ramón (1944), "Carácter originario de Castilla", Revista de estudios políticos, nº 1314, p. 383-408.

Milroy, James y Leslie Milroy (1999), Authority in Language: investigating Standard English, Londres/ Nueva York, Routledge. [1 ed., 1991.]

Mukarovsky, Jan (2000), "Standard Language and Poetic Language", en The Routledge Language and Culture Theory Reader, Londres/Nueva York, Routledge, p. 225-230. 
Moreno Cabrera, Juan Carlos (2008), El nacionalismo lingüístico, Barcelona, Península.

Pérez, Francisco Javier (2000), Diccionarios, recursos etnográficos, universos léxicos: propuestas teóricas para la comprensión cultural de los diccionarios, Caracas, Universidad Católica Andrés Bello.

Pérez, Francisco Javier (2005), Pensary hacer el diccionario, Caracas, Los libros del Nacional.

Regueiro, Manuel (2009), Fuentes del mundo literario de Camilo José Cela, Ph.D. dissertation, Austin, Texas Tech University.

Rojo, José Andrés y Miguel Mora (2001), "Cela repitió su discurso de Zacatecas de 1997, que era igual a otro de 1992”, El País, 19 de octubre, p. 21.

Salvador, Gregorio y Juan R. Lodares (2008), Historia de las letras, Madrid, Espasa Calpe. [1 ed., 1996.]

Santamaría, Luisa y María Jesús Casals (2000), La opinión periodística: argumentos y géneros de la persuasión, Madrid, Docencia.

Seoane, María Cruz (2008), "Columnistas que aún no se llamaban así", en Teodoro León Gross y Bernardo Gómez Calderón (eds.), El artículo literario: Manuel Alcántara, Málaga, Universidad de Málaga, p. 23-26.

Sinova, Justino (2006), La censura de prensa durante el franquismo, Madrid, Mondadori.

Smith, Anthony D. (2010), Nationalism: Theory, Ideology, History, Cambridge (Reino Unido)/Malden (Massachussets), Polity. [1ªd., 2001.]

Soldevila Durante, Ignacio (1990), "La creatividad léxica de Camilo José Cela", Hispanística, vol. 20, n॰8, p. 103-118.

Staal, Rein (1987), "The Irony of Modern Conservatism", International Political Science Review, vol. 8, n०4, p. 343-353.

Suárez Solís, Sara (1969), El léxico de Camilo José Cela, Barcelona, Alfaguara.

Thomas, George (1991), Linguistic Purism, Nueva York, Longman.

Umbral, Francisco (1996), Ramón y las vanguardias, Madrid, Espasa Calpe. [1ªd., 1978.]

Valls, Fernando (2002), "Cela, en sus artículos", El País, 21 de enero, disponible en http://elpais.com/ diario/2002/01/19/cultura/1011394805_850215.html. [Sitio consultado el 15 de marzo de 2014.]

Van Dijk, Teun A. (2005), Ideología: una aproximación disciplinaria, Barcelona, Gedisa. [1ed., 1998.]

Woolard. Kathryn A. (2001), "Introduction: Language Ideology as a Field of Inquiry”, en Bambi Schieffelin, Kathryn Woolard y Paul V. Kroskrity (eds.), Language Ideologies: Practice and Theory, Nueva York, Oxford University Press, p. 3-49.

Woolard, Kathryn A. (2007), "La autoridad lingüística del español y las ideologías de la autenticidad y el anonimato", en José Del Valle (ed.), La lengua, ¿patria común? Ideas e ideologías del español, Madrid/Fráncfort, Iberoamericana/Nervuert, p. 129-142. 